\title{
\#EdTechHub
}

Realising the potential of technology in education

\section{Using EdTech in Settings of Fragility, Conflict, and \\ Violence: A Curated Resource List}

Saalim Koomar, Caitlin Moss Coflan, Tom Kaye

EdTech Hub, https://edtechhub.org

Helpdesk Request Response No. 011

2020-06-03

DOI: 10.5281/zenodo.3885806

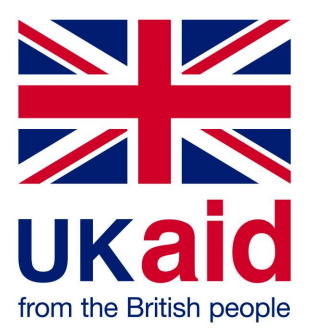




\section{About this document}

Recommended Saalim Koomar, Caitlin Moss Coflan, Tom Kaye (2020). Using EdTech in citation. Settings of Fragility, Conflict, and Violence: A Curated Resource List (EdTech Hub Helpdesk Response No 8). DOI: 10.5281/zenodo.3885806. Available under Creative Commons Attribution 4.0 International, https://creativecommons.org/licenses/by/4.0/.

Licence. Creative Commons Attribution 4.0 International

https://creativecommons.org/licenses/by/4.0/.

You - dear readers - are free to share (copy and redistribute the material in any medium or format) and adapt (remix, transform, and build upon the material) for any purpose, even commercially. You must give appropriate credit, provide a link to the license, and indicate if changes were made. You may do so in any reasonable manner, but not in any way that suggests the licensor endorses you or your use.

Creative

Commons

Acknow-

ledgement

Identifier

Notes.
N/A

\section{5:BTWBKYN7; 10.5281/zenodo.3885806}

You can contact the EdTech Hub here: https://edtechhub.org/hello/. 
2. Background 3

3. Key observations 3

4. EdTech interventions in FCV contexts $\quad 4$

4.1. Educational content and devices 4

4.1.1. Can't Wait to Learn, War Child 4

4.1.2. Rumie 5

4.1.3. Interactive Radio Instruction 5

4.1.4 Curious Learning 5

4.1.5. Aliim 6

4.1.6. Re:Coded 6

4.1.7. Nafham 6

4.2. System administration

4.2.1. Middle East Education, Research and Training Support (MEERS) 7

4.2.2. Room to Learn 7

4.3. Teacher Professional Development

4.3.1. Blended learning approach to develop the teachers' TPACK 7

4.3.2. Accelerating Equitable Access to School, Reading, Student Retention and Accountability

4.4. Resource libraries 8

4.4.1. Kolibri 8

4.4.2. Connect to Learn 9

4.4.3. Localising OER in Afghanistan: Developing a multilingual, digital library for Afghan Teachers 9

4.4.4. OER Commons Arabic 10

$\begin{array}{ll}\text { 5. Further reading } & \mathbf{1 0}\end{array}$

5.1 Technical Note on Education During the COVID-19 Pandemic (2020) Inter-agency Network for Education in Emergencies (INEE) 10

$5.2 \mathrm{FHI} 360$ (2019) Education in Emergencies fact sheet 10

5.3 Tauson \& Stannard (2018) EdTech for Learning in Emergencies and Displaced Settings: A Rigorous Review and Narrative Synthesis 10

5.4 USAID (2020) Delivering Distance Learning in Emergencies: A Review of

$\begin{array}{ll}\text { Evidence and Best Practice } & 10\end{array}$

5.5 International Rescue Committee Safe Healing and Learning Spaces Toolkit 11 


\section{Document purpose}

This curated list of resources collates interventions that effectively deploy education technology in settings of fragility, conflict, and violence (FCV). The World Bank (2020) states that by 2030 FCV settings will be home to up to two thirds of the world's extreme poor; these settings have become increasingly complex over the past decade, with the COVID-19 pandemic threatening to exacerbate existing challenges. This list explores effective uses of EdTech in FCV settings. It particularly emphasises interventions and evidence relevant to the Middle East and North Africa (MENA) region and distance learning during the COVID-19 crisis. These resources were selected with the intention to include practical recommendations on technology-enabled interventions.

\section{Background}

Estimates suggest there are roughly 535 million children currently living in settings of FCV. Children in these settings are roughly three times more likely to be out of school than children living in stable, low-income countries (Tauson \& Stannard, 2018). Within the Middle East and North Africa (MENA) region, Hammud \& Jarrar (2017) state that high levels of illiteracy contribute to conflict and violence. This finding reinforces the need for national education strategies to be underpinned by a focus on enhancing literacy. Regarding EdTech specifically, the overwhelming consensus is that technology is a tool which can be used to support, facilitate and enable good teaching and quality learning (Dahya, 2016). However, technology is only one of many inputs needed to lead to sustained improvements in learning outcomes.

This brief explores how EdTech, and education programmes more widely, can be leveraged to support distance and alternative learning opportunities that are urgently needed.

\section{Key observations}

In the process of developing this list, we have made several observations on initiatives and evidence related to EdTech in FCV contexts. Key findings include the following:

- There are promising tools and learnings to take from the listed interventions. Further research and discussion are required to appropriately adjust these interventions in line with specific country operating environments..

- Many EdTech initiatives do not adapt programme design sufficiently for FCV settings and have limited impact. This list has selected interventions which explicitly target these spaces.

- Various interventions are focused on 'hardware dumping' despite the lack of an evidence base around hardware interventions enhancing learning outcomes. Hardware solutions are particularly problematic when faced with the interconnected lack of access to power and connectivity in FCV contexts.

- Evidence of the use of technology to support out-of-school children in FCV settings within the MENA region is scarce. However, there are some regional 
EdTech programmes with linguistically relevant content that have the potential to be adapted for operational delivery in the MENA region.

- Effective EdTech interventions specifically targeting the most marginalised children within FCV settings are lacking. However, interventions that do not necessarily use technology but that do target important aspects of education systems, such as community engagement, and teacher professional development, have an important role to play in FCV settings. We have included several such interventions, which address equity issues.

- A lack of programmatic impact data in FCV settings clouds the picture around successes and learnings from specific projects (Tauson \& Stannard, 2018).

- In response to the COVID-19 pandemic, several resources specifically targeting education in FCV contexts have been published. They provide clear and practical frameworks for practitioners and policymakers. It is expected that the literature on distance learning in FCV contexts will continue to grow. These resources, among others, are presented in the 'Further reading' section of this brief.

\section{EdTech interventions in FCV contexts}

This section lists the various interventions located in FCV settings and is divided into four subsections:

1. Educational content and devices

2. System administration

3. Teacher professional development

4. Resources libraries

\subsection{Educational content and devices}

This subsection explores interventions utilising educational content and devices to enhance learning outcomes in FCV settings.

\subsubsection{Can't Wait to Learn, War Child}

The Can't Wait to Learn initiative uses custom gaming technology to deliver education to conflict-affected children in Sudan, Uganda, Lebanon, Jordan, Chad and Bangladesh. The programme partners closely with ministries of education, and aims to reach millions of children globally by 2023, closing the education gap in both formal and out-of-school settings. Can't Wait to Learn uses a delivery system that operates in low-infrastructure environments and places an emphasis on co-created programme design. The programme was co-designed with Sudanese stakeholders, and initial trialling in Sudan alongside published research has shown promising evidence, (Stubbé et al., 2016; War Child Holland et al., 2016). The programme is available in both Arabic and English with development in French in progress.

Key Considerations: The learning from initial trials offers foundational evidence of positive educational outcomes in an FCV context. Furthermore, the programme has relevance to the MENA region as it is already being deployed within the region and in Arabic. 


\subsubsection{Rumie}

Rumie aims to remove barriers to learning by using technology to freely share quality educational resources with those who have the most to gain by it. In 2015, Rumie launched Learn Syria, a project which collates learning resources relevant to Syrian children. Working with local partners and thousands of skilled volunteers online, Rumie built a fully digitised Syrian curriculum for children from grades 1-12. This allowed students to autonomously study by loading content onto learning tablets that work fully offline and asynchronously collect impact data.

Key considerations: While there is a lack of readily available impact data regarding the Learn Syria project, the establishment of Learn Syria followed Rumie's successful project EduOverEbola in Liberia during the Ebola crisis. EduOverEbola reached over 500 children during the Ebola crisis following mass school closures, raising $\$ 25,000$ in one month to deliver this rapid response. Rumie has also delivered a project in Afghanistan, Books to Bytes, widening the case for delivery in FCV contexts. Furthermore, the ability to access Rumie materials offline extends access to those children without internet.

\subsubsection{Interactive Radio Instruction}

From 2005-2011, the Somali Interactive Radio Instruction Program (SIRIP), provided Interactive Radio Instruction (IRI) to 330,000 children in Grades 1-5 attending formal, non-government, Koranic and community schools (Carlson, 2013). Radio programmes were broadcast daily (three hours per day, up to five days per week) or supplied to students and teachers on digital media players. Basic literacy and numeracy skills were covered, along with life skills, health, conflict prevention and mediation with 30-minute programmes addressing a particular learning objective. Readers and teachers' guides were provided, along with teacher training in active learning pedagogy. Results were positive as grade one SIRIP learners scored 15 per cent higher than non-SIRIP learners on standardised literacy tests, and 20 per cent higher in maths. Furthermore, SIRIP helped stabilise fragile communities by providing a consistent, attractive and reliable service.

Key Considerations: IRI can represent a good, short-term investment that enables governments to deliver the core curriculum and facilitate teacher professional development in support of long-term education improvement. It is a low-cost, adaptive and accessible EdTech modality that can be tailored to specific contexts. However, it is important to note that linguistic aspects are vital to the success of IRIs. A similar programme, the Southern Sudan Interactive Radio Instruction (SSIRI), was launched in 2004 and had contrasting results, with teachers' proficiency in English hindering impact of the service. USAID have recently collated a selection of Interactive Audio Instruction (IAI) and IRI materials for free download and use, including content for South Sudan and the DRC. For further reading on the use of IRI to mitigate the impact of COVID-19, please see McBurnie (2020), here.

\subsubsection{Curious Learning}

Curious Learning works with partners to curate, localise and distribute free open source apps that empower everyone to have the opportunity to learn to read. Examples of initiatives include creating SMS, email and social media campaigns to drive parent 
downloads of apps for children and localising apps such as Feed the Monster which has been translated into over 45 languages.

Key Considerations: Given the illiteracy challenges within the MENA region, Curious Learning could support the process of honing in on particular interventions that would improve literacy rates. They cite programmes hosted in Nigeria and other FCV contexts with sufficient impact measurement data to support deeper analysis.

\subsubsection{Aliim}

Aliim is a non-profit organisation aiming to leverage technology and mentors to provide refugees and marginalised youth access to safe, quality and relevant education. Aliim focuses on the 400,000 school-aged Syrian children who are out of school. It uses mobile learning via smart phones to address this crisis, aiming to improve equity, learning and minimise costs. Through this approach, Aliim has developed the first curriculum framework for mobile learning in conflict-affected contexts.

Key considerations: With experience targeting refugee children in Jordan and Lebanon, Aliim offers a regionally-appropriate EdTech solution aligned with curricula. However, the need for a smartphone in order to access Aliim content significantly reduces the potential for marginalised communities to benefit from it.

\subsubsection{Re:Coded}

Re:Coded prepares conflict-affected youth to enter the digital economy as software developers and tech leaders in their communities. Re:Coded has trained more than 450 children and youth how to code since it was founded in May 2017. The company currently operates in Iraq, Turkey and Yemen.

Key considerations: The three Re:Coded hubs are located in Yemen, Iraq and Turkey (Global Innovation Exchange). Re:Coded may well have valuable contextual learnings to offer on the successful implementation of an EdTech initiative in-country. Further research on the programme's impact, and a better understanding of the users it reaches, is required.

\subsubsection{Nafham}

Nafham is a free, online, $\mathrm{K}-12$ crowdsourced educational platform that receives over 600,000 unique visitors every month. It uses over 23,000 videos to cover Egyptian, Saudi, Algerian, Syrian \& Kuwaiti curricula.

Key considerations: The scaled nature of Nafham across the MENA region demonstrates significant reach and potential for further expansion. The platform's expansion to Syria was specifically targeted at conflict-affected, out-of-school children with access to the internet. While Nafham holds promise for children with access to the internet, it is unlikely to reach more marginalised learners who lack access to online resources. Regarding K-12 Education, a further resource of note is Edraak, which offers free online education in Arabic for learners and teachers. 


\subsection{System administration}

This subsection explores interventions which focus on education systems within FCV settings.

\subsubsection{Middle East Education, Research and Training Support (MEERS)}

MEERS aims to provide on-going data and research to better understand and address the educational and psychosocial needs of refugee children in the MENA region. MEERS provides teachers with training and resources, conducts rapid assessments for decision-making in fluid situations, provides real-time data collection and analysis, and fills in knowledge gaps on region-specific early grade literacy and numeracy, early childhood education and youth development.

Key considerations: MEERS largely focuses on education access, relevance and quality issues stemming from the conflicts in Iraq, Syria, and Yemen. Outputs of the programme include an Education Data Snapshot of Yemen - a digitised contextualisation of the education space in Yemen. Building out this initiative through leveraging existing data to develop more targeted programmes could include data collection of community facilities and schools, categorised by accessibility, such as the one in this school census project in Sierra Leone (Namit \& Mai, 2019).

\subsubsection{Room to Learn}

The Room to Learn (RtL) project in South Sudan aimed to increase equitable access to education in crisis and conflict environments for 15 million learners by 2015. RtL used a community-based, learner-centered approach to reach marginalised populations, with a focus on both formal and alternative education systems. The project included parent-teacher association capacity building, school development planning, and teacher professional development with a focus on literacy. Grants and support were provided to help develop safe and inclusive learning spaces.

Key considerations: Though not an EdTech solution, RtL is an example of an education development intervention in an FCV setting with a strong focus on equity, inclusion and community participation to support the most marginalised learners. While the project did not use high-tech solutions, it exemplifies the types of investments that can help complement and make EdTech-enabled interventions more effective. Materials were developed to build capacity and enhance pedagogy, including leveled readers, all aligned to the South Sudanese curriculum.

\subsection{Teacher Professional Development}

This subsection examines aspects of training to support enhanced pedagogy and subject knowledge in FCV countries.

\subsubsection{Blended learning approach to develop the teachers' TPACK}

Technological Pedagogical Content Knowledge, or TPACK, is a blended learning approach which integrates technology into existing teaching practice in order to 
enhance teaching and learning. A 2016 study conducted by Qasem and Viswanathappa aimed to determine the levels of ICT knowledge on e-course design through a blended learning approach among secondary school science teachers in Yemen. The study found that:

1. TPACK provided a valuable tool to assess teacher knowledge in technology integration.

2. Teachers' ICT knowledge was above average in two groups.

3. There was a significant difference between experimental and control groups on the ICT knowledge scale.

As such, the study found that TPACK's blended learning instructional approach enhanced teacher performance.

Key considerations: The study focuses on pedagogy related to the use of technology in education in Yemen. Its findings are particularly important given the noted lack of empirical data within this space. However, the relatively small sample size (60 teachers), limited the scope of the study (it only focused on science, no other subjects), and lack of focus on conflict and out-of-school children constitute significant limitations in the applicability of the study's findings in relation to the scope of this list. Even so, TPACK offers an illustration of the importance of interventions focused on teachers' digital skills and preparedness to use technology, and the study recommends developing online collaborative tools in line with TPACK as further research.

\subsubsection{Accelerating Equitable Access to School, Reading, Student Retention and Accountability}

The Accelerating Equitable Access to School, Reading, Student Retention and

Accountability (ACCELERE!) project is improving access to education and learning outcomes for more than one million boys and girls in the Democratic Republic of Congo (DRC). The project aims to improve reading outcomes by developing instructional materials, enhancing teacher pedagogy, creating safe learning spaces and working with the government to strengthen accountability systems and education policies. ACCELERE! translated evidence-based, early-grade reading curriculum and materials into local languages (Kiswahili, Lingala, and Ciluba) and French.

Key considerations: An ongoing project, ACCELERE! is not an intervention centred on EdTech. However, the objectives, set within an FCV context, alongside the currency of this intervention, make it a relevant programme to include on this list.

\subsection{Resource libraries}

This subsection highlights interventions centred on resources developed for children in affected areas experiencing fragility, conflict and violence.

\subsubsection{Kolibri}

Kolibri is an offline app that works in low-resource communities designed to provide offline access to a curated and openly licensed educational content library. It is hardware-agnostic and provides offline access to its educational content library in 23 countries for over 6 million users. Kolibri is adapted to reach the most remote 
communities; when exported onto a device, it can be carried by foot to share installers, updates, and content with other devices over local networks

Key considerations: Kolibri is available in dozens of languages, including Arabic, and has been used in non-formal school systems and refugee camps. The customisable digital curriculum means it can be adapted and tailored where necessary with a content curation system that ensures users have full control over the organisation of educational materials. Co-dependent software components include a targeted tool for curriculum specialists at Ministry-level and a tool for school administrators at classroom-level.

\subsubsection{Connect to Learn}

Connect to Learn (CtL) is a public-private partnership aiming to increase access to quality education. The initiative, which especially targets girls, aims to build life skills and integrate technology tools and digital learning resources in schools. The International Rescue Committee (IRC) launched CtL in ten schools in the Domiz refugee camp in the Kurdish region of Iraq, targeting 160 Syrian refugee teachers. The IRC partnered with Ericsson and AsiaCall to provide ICT hardware and connectivity via a cloud-based server and the internet. Teachers are provided with access to resources to support pedagogy designed for children affected by conflict, which includes social-emotional skills, literacy and numeracy. Teachers have access to training materials prepared by the IRC, and can use the technology to connect to each other and share experiences.

Key Considerations: Iraq and South Sudan currently host CtL projects within the MENA region. CtL also operates in Burkina Faso, another FCV setting. Internet connectivity is required for $\mathrm{CtL}$ to function, which limits accessibility for marginalised groups.

\subsubsection{Localising OER in Afghanistan: Developing a multilingual, digital library for Afghan Teachers}

This online library is the first open educational resource (OER) initiative in Afghanistan; it was established to enhance teacher subject knowledge and access and use of learning materials. It also aims to foster more diverse teaching methodologies in order to improve learning outcomes in Afghan classrooms (Oates \& Hashimi, 2016). The intervention shows how OER can be customised for multilingual, resource-scarce contexts.

Key considerations: Lessons can be learned from the attempts to overcome resource constraints through the development of OER tailored to the Afghan context. The openly licensed nature of these resources means they can be retained, revised, remixed, reused and redistributed. Using OER ensures learning materials are available, rapidly, at low-cost. They can also be easily adapted to local contexts to target the needs of specific groups, which is particularly useful in FCV contexts where fast action is necessary. Adapting for use, however, will come with translation challenges given the content is currently in Dari and Pashto. 


\subsubsection{OER Commons Arabic}

The OER Commons Arabic is free to use and openly licensed and has 435 resources in subjects such as Islamic studies, art, poetry and literature, history and language. As it is an OER, resources on this platform can be created, shared and adapted freely.

Key considerations: There are several hubs and groups within the OER Commons Arabic that users can connect with. The open nature of the platform means that it can evolve and improve over time, with users contributing to the platform's overall provision of quality learning materials. However, there is a lack of evidence on the effectiveness of this platform within an FCV setting.

\section{Further reading}

\subsection{Technical Note on Education During the COVID-19 Pandemic (2020) Inter-agency Network for Education in Emergencies (INEE)}

This is a live document developed in response to changes in the education space following the COVID-19 pandemic. The paper specifically targets existing FCV contexts pre-COVID-19 to support children of school age with activities designed outside of the formal education space. The framework is for practitioners and policymakers. The document also provides a useful resource library for further relevant materials.

\subsection{FHI 360 (2019) Education in Emergencies fact sheet}

This fact sheet details programmes hosted in FCV settings using a context-sensitive, strengths-based approach. The fact sheet references applications of technical expertise in different settings. As well as providing a resource library to explore projects, data and evidence generation on Education in Emergencies in more detail.

\subsection{Tauson \& Stannard (2018) EdTech for Learning in Emergencies and Displaced Settings: A Rigorous Review and Narrative Synthesis}

This report provides an overarching view of Edtech in emergency contexts and identifies gaps within the existing literature, offering a nuanced understanding of what is required to implement effective and ethical EdTech programmes. The report interrogates how the utilisation of EdTech for teaching and learning (at home or at school) can best facilitate the learning process of children in crisis-affected settings.

\subsection{USAID (2020) Delivering Distance Learning in Emergencies: A Review of Evidence and Best Practice}

This review analyses the effectiveness of four distance learning modalities - radio / audio, video / television, mobile phone programming and online learning - that can be implemented during and beyond emergencies. 


\subsection{International Rescue Committee Safe Healing and Learning Spaces Toolkit}

This toolkit contributes to the overarching goal that children are safe, well and learning in emergencies. The toolkit provides child protection and education practitioners with all of the content needed to initiate safe healing and learning spaces. Practical resources are provided for those at the coal face of education provision in emergency settings.

\section{How this list was developed}

The resources listed meet the following criteria:

- Peer-reviewed articles or current policy guidance from established international bodies (e.g., World Bank).

- Interventions were identified in research papers produced by organisations such as Save the Children and USAID. These were supplemented by innovations listed on the Global Innovation Exchange and identified through the Inter-agency Network for Education in Emergencies (INEE).

- Actionable advice rather than abstract and theoretical ideas.

- Published after 2010.

- Reference at least one country classified as experiencing 'high' or 'medium' intensity conflict as defined by the World Bank's List of Fragile and Conflict-affected Situations (2020).

\section{References}

Abu Hammud, M., \& Jarrar, A. G. (2017). Fighting Illiteracy in the Arab World. International Education Studies, 10(11), 116. https://doi.org/10.5539/ies.v10n11p116

Ali, L. (2020, February 10). Responding to Iraq's learning crisis. UNICEF Connect. https://blogs.unicef.org/blog/responding-iraq-learning-crisis/

Carlson, S. (2013). USING TECHNOLOGY TO DELIVER EDUCATIONAL SERVICES TO CHILDREN AND YOUTH IN ENVIRONMENTS AFFECTED BY CRISIS AND/OR CONFLICT. 41.

Curious Learning. (2020). What We Do. Curious Learning. https://www.curiouslearning.org/what-we-do-2

Darakht-e Danesh. (2020). Darakht-e Danesh Online Library. https://www.darakhtdanesh.org/en

Ericsson. (2020, March 3). Sustainability \& Corporate Responsibility Report. Ericsson.Com. https://www.ericsson.com/en/about-us/sustainability-and-corporate-responsibi lity/sustainability-report

GDL Radio. (2020). GDL Radio. GDL Radio. https://gdlradio.org/ 
Global Partnership for Education. (2020). Education in Yemen.

https://www.globalpartnership.org/where-we-work/yemen

Huenteler, J. T., Khanna, A., Badiei, S., Matsuo, T. M., Maier, E., \& Fernstrom, E. M. (2017). Republic of Yemen - Restoring and expanding energy access: Power sector reengagement note (No. ACS22319; pp. 1-1). The World Bank.

http://documents.worldbank.org/curated/en/655811496412539032/Republic-of -Yemen-Restoring-and-expanding-energy-access-power-sector-reengagement-n ote

Humanitarian InSight. (2020). Global Humanitarian Overview 2020.

https://hum-insight.info/

Inter-agency Network for Education in Emergencies (INEE). (2016). Landscape Review: Education in Conflict and Crisis-How Can Technology Make a Difference?

https://inee.org/system/files/resources/20160303 Landscape Review ICT4E in Conflict and Crisis.pdf

Inter-agency Network for Education in Emergencies (INEE). (2020a). Coronavirus (COVID-19) Resources | INEE. https://inee.org/covid-19/resources

Inter-agency Network for Education in Emergencies (INEE). (2020b, March 26). Rapid Evidence Summary on Mass Communication |.

https://inee.org/resources/rapid-evidence-summary-mass-communication

Inter-agency Network for Education in Emergencies (INEE). (2020c). Technical Note: Education during the COVID-19 Pandemic. [Text].

https://inee.org/system/files/resources/INEE\%20Technical\%20Note\%20on\%20C OVID-19\%20EN\%202020-04-23.pdf

International Rescue Committee (IRC). (2016). Safe Healing and Learning Spaces Toolkit. https://rescue.app.box.com/s/f0djf7fa3yzbtn7vqt3ouv2mn20okt8l

Jalbout, M. (2015). Opportunities for Accelerating Progress on Education for Syrian Children and Youth in Jordan. 26.

Kabira, \& Thanh, T. M. (2019, February 6). Digital School Census in 10 Weeks? How it was done in Sierra Leone.

https://blogs.worldbank.org/education/digital-school-census-10-weeks-how-itwas-done-sierra-leone

Kolibri. (2020). Kolibri: A Free, Open Source Education for All | Learning Equality. https://learningequality.org/kolibri/

McBurnie, C. (2020). Using Interactive Radio Instruction to mitigate the educational impact of COVID-19: A curated resource list. EdTech Hub Helpdesk Response No. 02.

Muthanna, A., \& Sang, G. (2018). Brain drain in higher education: Critical voices on teacher education in Yemen. London Review of Education, 16(2), 296-307. https://doi.org/10.18546/LRE.16.2.09

Oates, L., \& Hashimi, J. (2016). Localizing OER in Afghanistan: Developing a Multilingual Digital Library for Afghan Teachers. Open Praxis, 8(2), 151-161. https://doi.org/10.5944/openpraxis.8.2.288 
Perry, K. H., \& Moses, A. M. (2011). Television, Language, and Literacy Practices in Sudanese Refugee Families: 'I learned how to spell English on Channel 18'. Research in the Teaching of English, 45(3), 278-307. JSTOR.

Qasem, A. A. A., \& Viswanathappa, G. (2016). Blended Learning Approach to Develop the Teachers' TPACK. Contemporary Educational Technology, 7(3). https://doi.org/10.30935/cedtech/6176

Re:Coded. (2020). Re:Coded. https://www.re-coded.com

Rumie Initiative. (2020). Rumie Initiative. https://rumie.org/impact/

Save the Children. (2018, March 14). EdTech for Learning in Emergencies and Displaced Settings: A rigorous review and narrative synthesis. Resource Centre. https://resourcecentre.savethechildren.net/library/edtech-learning-emergencie s-and-displaced-settings-rigorous-review-and-narrative-synthesis

Stubbé, H., Badri, A., \& Telford, R. (2016). E-Learning Sudan, Formal Learning for Out-of-School Children. 14(2), 14.

Thompson, D. E. (2019). Summative GPE country program evaluation (Batch 4, Country 9: Republic of South Sudan; p. 181).

https://www.globalpartnership.org/sites/default/files/document/file/2019-07-su mmative-gpe-country-program-evaluation-south-sudan.pdf

UNICEF. (2020, March). UNICEF Yemen Country Office Humanitarian Situation Report (Reporting Period: 1 - 31 March 2020) [EN/AR] - Yemen. ReliefWeb.

https://www.unicef.org/appeals/files/UNICEF Yemen Humanitarian Situation R eport 131 March 2020.pdf

United Nations. (2020a, May). COVID-19 Global Humanitarian Response Plan (Humanitarian response plan) | Financial Tracking Service.

https://www.humanitarianresponse.info/sites/www.humanitarianresponse.info /files/documents/files/ghrp-covid19 may update.pdf

United Nations. (2020b). COVID-19 Global Humanitarian Response Plan (Humanitarian response plan) | Financial Tracking Service.

https://www.humanitarianresponse.info/sites/www.humanitarianresponse.info /files/documents/files/ghrp-covid19 may update.pdf

USAID. (2020, April 24). Delivering Distance Learning in Emergencies | Education Links. https://www.edu-links.org/sites/default/files/media/file/DELIVERING\%20DISTAN CE\%20LEARNING\%20IN\%20EMERGENCIES.pdf

War Child Holland. (2020). Can't Wait To Learn. Warchild English. https://www.warchildholland.org/projects/cwtl/

War Child Holland, Afhad University for Women, \& TNO. (2016). Research Report for Phases I and II e-Learning Sudan (2012 - 2015) (p. 41).

World Bank. (2020, February 27). Classification of Fragile and Conflict-Affected Situations.

http://pubdocs.worldbank.org/en/179011582771134576/FCS-FY20.pdf 